\title{
When Is It Appropriate to Give Information about Turner Syndrome to Turner Girls?
}

Keihosuke Fujita, Ryoichi Nakajima, Hiroshi Murakami, Hiroshi Inada, Takuma Kondo, Yasuko Itagane and Gen Isshiki

Department of Pediatrics, Children's Medical Center, Osaka City General Hospital (KF, RN), Department of Pediatrics, Osaka City University Medical School (HM, HI, GI), Kondo Pediatric Clinic (TK), Osaka Ekisaikal Hospital (YI), Osaka, Japan

Key words: Turner syndrome, disease information

\section{Introduction}

Turner girls are affected by short stature and absence of puberty. However, they are not well informed about Turner syndrome (TS) in our country, mainly because of the cultural background. Information about TS is given only to parents on diagnosis. Turner girls may get information only about growth hormone and estrogen therapy. Full information about TS is given to Turner girls at the age of 8 to 10 years in the United States or Europe, and they accept it well (personal communication from Bente Konradsen, Denmark). We have organized a family association of TS since 1991. The members consist of about 70 families from all over Japan. The meetings are held about twice a year. Ten adult Turner women have attended these meetings. We asked these Turner women when it is appropriate to give information about TS to Turner girls.

Correspondence: Dr.Keinosuke Fujita, Department of Pediatrics, Children's Medical Center, Osaka City General Hospital, 2-13-22, Miyakojima-Hondori, Miyakojima-ku, Osaka 534 Japan

\section{Material and Methods}

The questions were sent to ten Turner women, and seven answers were returned. The questions were: 1 ) when is it appropriate to give information about TS to Turner girls? 2) how should be informed? 3) how old were they when they got full information about TS?, 4) how do they know about TS? 5) what were their reaction when they knew about TS?

\section{Results}

1. When is it appropriate to give information about TS to Turner girls?

Four women answered that the appropriate time to give information was 10 to 13 years old. Three women answered that the appropriate time was about 20 years old.

\section{How should they be informed?}

Four women answered that the information should be given by their parents. Two women answered that it should be given by doctors. One answered that it depended on the patients.

3. The age when these Turner women received full information about $T S$.

The answers were $13,14,16,17,19,20$, 
and 20 years old.

\section{How did they knew about their diagno- sis as TS?}

Four women were informed by their parents. Two women knew about TS when they looked at their medical charts. One woman heard of TS accidentally when her parents talked to each other.

\section{Some comments when they knew about TS.}

a) I was treated with growth hormone, and I understood that I had some abnormality that caused by short stature. I did not feel any shock when I heard about TS, since I had a normal puberty. I am a student nurse. I do not suffer from any harassment at present.

b) I felt a shock when I heard about the final short stature of TS at the age of 10 years. I did not feel any shock when I heard about the chromosomal abnormality. I was stressed when I played sports with my friends. An equal relationship with other people is so important, but it is difficult for me.

c) I felt something wrong because of my absence of puberty. I was shocked when I knew about TS from my medical chart. But I feel better now because I know the cause of my condition. I still feel anxious about marriage and pregnancy.

d) I imagined that I would be taller, and would reach puberty someday. But I lost hope when I knew about TS. I feel how happy other people are. Nobody understands me. I hope people will understand more about TS. I still think that happiness for a woman is to be married and to have a baby.

e) I had growth hormone therapy before I knew about TS. I did not feel shocked when I knew about TS. I am enjoying my college life.

f) I asked my mother whether I had a chromosomal abnormality when I learned about chromo- somes at junior high school. Mother answered, "Yes, you have," and I was informed about TS. I felt better when I knew that the mentality in TS is normal. The parents should not keep TS secret from their daughter. If they do, she will feel that TS is a bad thing. A person with TS has a right to know about it.

g) I hoped that I would be taller than $150 \mathrm{~cm}$. I was anxious about puberty when I heard about TS, and now I am anxious about marriage.

\section{Discussion}

Half of Japanese Turner women considered that information about TS should be given at the age of 10 to 13 years, almost the same time as in the United States or Europe; but the other half of Japanese Turner women considered that information about TS should be given at the age of 20 years. Parents and doctors are afraid that Turner girls develop unnecessary anxieties. In Japan, doctors and family do not give full information to patients suffering from high risk disease, such as cancer. Recently, the final height of Turner girls is known to be improved by growth hormone therapy. Oocyte donation, in vitro fertilization, and embryo transfer are being performed successfully on Turner women in the United States and Europe. Turner girls can get such information at present. In the past, they could only be informed that there was no way to improve final height or to get pregnant. From our comments by Turner women, they seem to accept it well when they know about TS. Half of Japanese Turner women considered that Turner girls should be informed about TS at the age of 10 to 13 years. The other half of Japanese Turner women still considered that Turner girls should be informed about TS at about 20 years. 